\title{
Tourisme communautaire et diffusion d'une 'culture touristique' chez les Shuar de Chico-Méndez
}

Turismo comunitario y difusión de una "cultura turística" entre los Shuar de Chico-Méndez

Julie Carpentier

Doctora en Etnología. Centro EREA del LESC (UMR 7186), Universidad Paris-Ouest Nanterre La Défense. Instituto Francés de Estudios Andinos (UMIFRE 17, CNRS-MAE)

julie_carpentier@hotmail.fr

CLAVES DEL TURISMO DE BASE LOCAL

MONOGRÁFICO COORDINADO POR ESTEBAN RUIZ BALLESTEROS (Universidad Pablo de Olavide)

\section{RESUMEN}

Este texto propone abordar la dimensión de la "cultura turística" como factor determinante en el desarrollo del turismo comunitario. Basándose en un estudio de caso realizado en la comunidad shuar de Chico-Méndez (Amazonia ecuatoriana), intenta analizar el proceso de construcción y de reapropiación identitaria llevado a cabo por los habitantes con el fin de desarrollar su proyecto turístico, procurando mostrar de qué manera las prácticas turísticas se hicieron poco a poco una parte integrante de la cultura y son actualmente usadas por la población para identificarse étnicamente a escala "glocal". Este texto insiste, pues, en la dimensión dinámica de las identidades culturales y en el papel activo de las poblaciones huéspedes en la remodelación y redefinición de las identidades culturales mediante la actividad turística.

\section{ABSTRACT}

This article proposes to address the 'tourist culture' as a key factor for the development of community-based tourism. Based on a case study carried out in the shuar community of Chico-Mendez (Ecuadorian Amazon), it tries to analyze the process of identity construction and re-appropriation led by locals to develop their tourism project, seeking to show ways in which tourism practices have gradually become an integral part of the culture and how these practices are being used by the population to identify themselves ethnically at 'glocal' level. This text therefore insists on the dynamic of cultural identity, and on the active role of host populations in remodeling -or even in the redefinition- of cultural identity through tourism.

PALABRAS CLAVE

turismo comunitario | Shuar | Ecuador | cultura turística

KEYWORDS

community-based tourism | Shuar | Ecuador | tourism culture

\begin{abstract}
"Nous ne nous mettons pas uniquement en scène face aux touristes pour faire le commerce de notre culture mais également pour que ce peuple puisse s'identifier et valoriser sa culture (...). Je suis Shuar, je me sens fier d'être Shuar et quand un touriste vient dans ma communauté il apprend à connaître notre vraie culture, nos racines. Et grâce aux anciens qui connaissent la médecine, les chants, les légendes, etc., nous apprenons. C'est pour cela que nous travaillons à Ikiam" (Pedro Tzerembo, Arajuno, 25 mai 2011).
\end{abstract}

C'est en ces termes que Pedro Tzerembo, leader de la communauté shuar de Chico-Méndez et de l'association Ikiam justifie le développement du tourisme dans sa communauté en présentant cette activité autant comme une ressource économique que comme un outil permettant à la population de se réapproprier son identité ethnique et de valoriser sa culture. En d'autres termes, les pratiques culturelles touristifiées souvent jugées folklorisantes semblent ici s'inscrire dans un processus de réappropriation et de valorisation remettant ainsi en question la dichotomie "culture pour soi/culture pour le touriste" longtemps mise en avant dans les études sur le tourisme (Boullosa, Demanget et Dumoulin 2010: 24). Picard (1992) est le premier à avoir proposé la formule de "culture touristique" afin de désigner les cas où les pratiques touristiques sont devenues une partie intégrante de la culture et l'interaction avec les touristes un élément central dans la définition de l'identité ethnique. L'analyse de Picard amène 
notamment à s'interroger sur le rôle du tourisme dans le processus de formation des identités mais également, et dans une autre mesure, sur son rôle dans l'avènement d'une conscience réflexive de la culture. Comment la touristification travaille-t-elle la société de l'intérieur? Dans quelles mesures la dimension de la "culture touristique" peut-elle se convertir en un facteur déterminant pour le développement du tourisme communautaire? En me basant sur une étude de cas menée dans la communauté de Chico-Méndez entre 2009 et 2011, je chercherai à mettre en perspective la représentation que les Shuar offrent de leur culture aux touristes et la représentation qu'ils s'en font lorsqu'ils parlent du tourisme.

\section{La communauté shuar de Chico-Méndez et le tourisme}

La communauté de Chico-Méndez s'est lancée dans l'activité touristique en 2009 en proposant aux touristes de découvrir les richesses naturelles et culturelles de la région. Elle accueille des groupes occasionnellement au sein de son centre de tourisme communautaire (CTC) situé à $15 \mathrm{mn}$ du centre de la communauté. Le CTC Ikiam reçoit en moyenne un groupe de deux à quatre touristes étrangers par mois (deux à trois jours) ainsi que des groupes de touristes nationaux venant le week-end en famille. Une fréquentation que l'on peut donc qualifiée de faible, le tourisme restant une pratique occasionnelle permettant à la population locale de compléter ses revenus sans pour autant délaisser ses activités quotidiennes dédiées principalement à l'agriculture.

La communauté shuar de Chico-Méndez se situe dans le canton d'Arajuno (province de Pastaza), à $8 \mathrm{~km}$ au sud-est de la ville d'Arajuno, chef-lieu de canton (Figure 1). Cette région, située sur le piémont amazonien des Andes orientales se caractérise par un terrain escarpé, vallonné avec des altitudes pouvant atteindre plus de $1000 \mathrm{~m}$. Elle se compose d'un vaste réseau hydrographique dont le principal bassin versant est la rivière Arajuno au bord de laquelle s'étend la ville d'Arajuno.

La communauté de Chico-Méndez se compose de 26 familles, réparties sur un territoire de 1700 hectares principalement composé de forêts primaires et secondaires. Les habitations se situent en majorité le long de la route traversant la communauté, laquelle permet un accès direct à la ville d'Arajuno. Les maisons sont construites en bois avec un toit en tôle ou en feuilles de palmiers. Elles ont accès à l'eau et l'électricité. Le centre de la communauté se compose quant à lui d'une école, d'une chapelle et d'un terrain de football où les habitants organisent, chaque année, la fête de la communauté. La zone est entretenue par la population elle-même au cours de journées de travail communautaire (minga), lesquelles sont généralement organisées le dimanche. Malgré la proximité de la ville, une partie de la population vit à temps partiel ou temps complet à Arajuno pour raisons professionnelles, pour faciliter l'accès au collège et lycée à leurs enfants ou encore bénéficier des services offerts par la ville (centre de santé, institutions, magasins, accès internet, etc.). Les membres de ces familles retournent néanmoins très régulièrement (voire quotidiennement) dans la communauté où ils possèdent une maison et des terres qu'ils exploitent pour leur consommation personnelle ou, en cas d'excédent, pour vendre leurs produits en ville.

Lorsque qu'un groupe de touriste visite le CTC, la communauté s'organise afin d'offrir le meilleur séjour possible aux visiteurs, insistant notamment sur la partie culturelle qui est particulièrement mise en valeur. A lkiam, la cérémonie d'accueil est notamment très exotisée: vêtus de leurs Itip (habit traditionnel shuar), deux ou trois membres de la communauté s'approchent des touristes, armés de leurs lances. Au premier cri: "Giriste", les hommes lèvent leurs lances en direction des visiteurs, puis les retirent au deuxième cri: "Girista". Cette tradition, qui est davantage ressentie comme une attaque pour des étrangers, est au contraire un moyen de souhaiter la bienvenue aux nouveaux hôtes. Le premier contact plonge donc les visiteurs dans un autre univers, où leurs repères se trouvent tout à coup modifiés, la sensation d'agression se révélant être une marque de respect et de bienvenue. A partir de là, les touristes comprennent qu'ils viennent d'entrer en territoire étranger, un territoire qui leur est cependant grand ouvert et où ils ont tout à apprendre.

Les activités proposées à Ikiam tout au long du séjour sont diverses et touchent autant au domaine naturel que culturel. Les matinées sont généralement réservées aux activités liées de près ou de loin à la découverte de la flore et de la faune. La visite du saladero (1) et celle de la cascade sacrée Arutam font ainsi partie des activités phares proposées par Ikiam. Ces expéditions nécessitent $1 \mathrm{~h} 30$ de marche en 
moyenne et sont l'occasion d'observer la nature environnante et de découvrir le rapport que la population shuar entretient avec elle. On trouve dans la forêt et aux abords du CTC une grande variété d'espèces d'arbres et de plantes utilisés par la population locale sous différentes formes (construction, médecine, aliments, etc.).

Figure 1: Localisation du CTC Ikiam

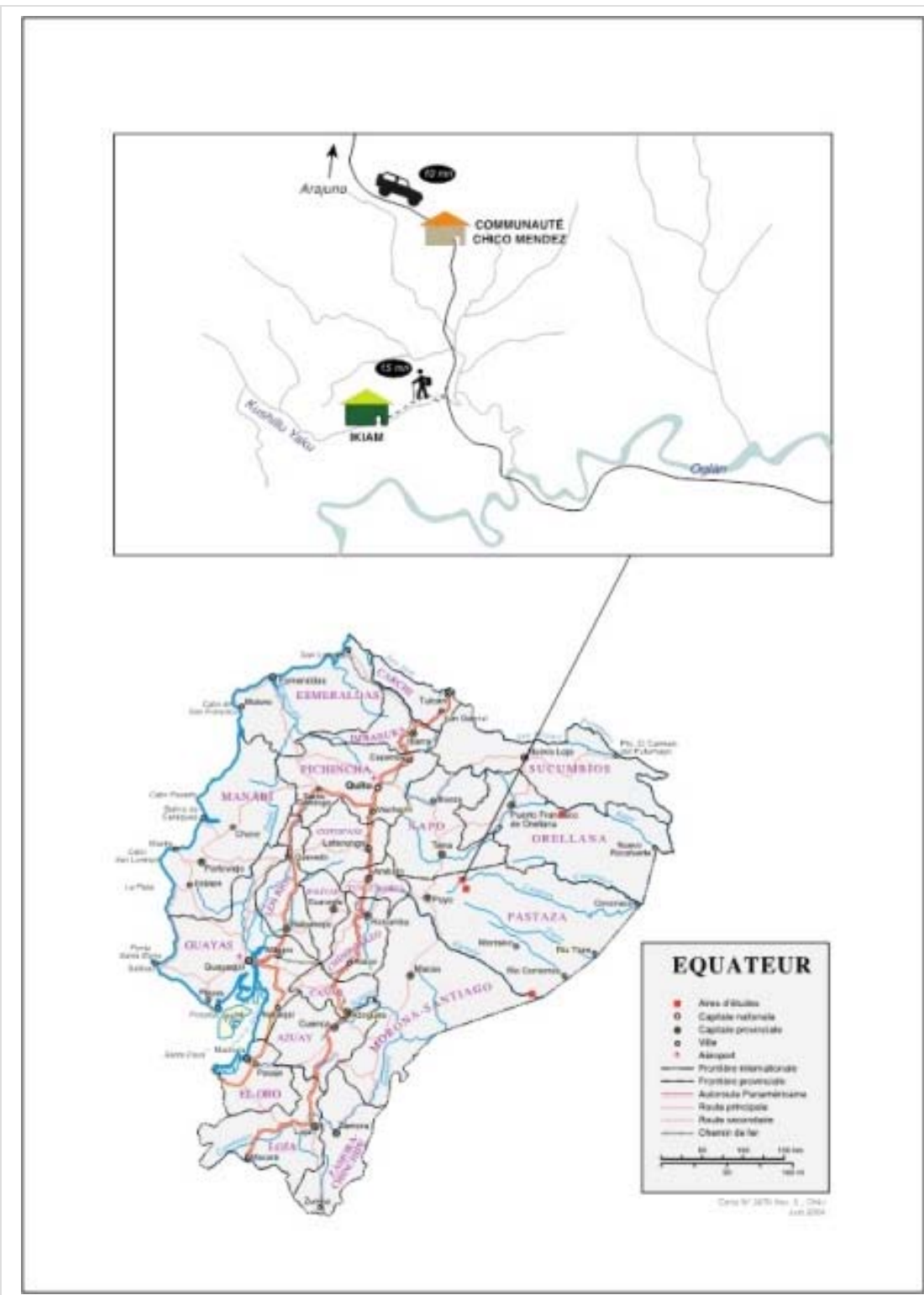

Élaboration: Julie et Chloé Carpentier, 2016

Les touristes sont également invités à découvrir certaines pratiques de la vie quotidienne (participation aux mingas, entretien des jardins, préparation de plats typiques, etc.) mais aussi à élaborer l'artisanat local (paniers en fibres naturelles, poteries, etc.) ou encore à pratiquer la sarbacane et/ou la lance. Au cours de cette activité, une cible est généralement posée à une distance raisonnable que les touristes tentent d'atteindre. Cet atelier se déroule en fin de séjour. II est également l'occasion pour les touristes de se faire peindre le visage à base d'un pigment rouge issu des graines du roucou (ou achiote en Équateur), une espèce d'arbre endémique.

Les repas sont aussi l'occasion de faire découvrir la diversité culinaire du lieu. Les produits gastronomiques font en effet partie du patrimoine des populations visitées, ils sont un révélateur identitaire, au même titre que les différentes activités culturelles proposées au cours du séjour. A lkiam, le maïto de poulet ou de poisson est un plat typique fréquemment servi. Les aliments (viande ou poisson accompagnés de cœur de palmier ou de manioc) sont cuits au feu de bois dans une feuille de palmier. Ikiam propose également de goûter aux larves de palmier, un met apprécié des locaux, mais qui rebute la 
majorité des touristes.

Une fois le dîner servi dans la maison communautaire, la soirée se poursuit autour d'un feu par des échanges culturels entre les hôtes et les touristes : histoires et légendes shuar, cérémonie et rituels du chaman (uwishin), démonstration de danse traditionnelle, etc.

En fin de séjour, les touristes sont également invités à visiter le musée, appelé "maison des savoirs ancestraux" dans lequel se trouve une multitude d'objets et d'instruments de musique faisant référence à la culture shuar. II peuvent également acheter des souvenirs dans la boutique appelée "maison de l'artisanat" (bracelets, colliers, boucles d'oreilles, poteries, etc.), artisanat confectionné par la population locale elle-même. Il est intéressant d'observer que l'on trouve quasiment les mêmes objets dans ces lieux distincts (excepté ceux ayant intégré des matériaux modernes comme les perles en plastique exclusivement exposés dans la "boutique"). Dans l'un, la "boutique", on vend et on met en avant la qualité du travail effectué par l'artisan. Dans l'autre, le "musée", on explique son usage traditionnel, son histoire, en insistant sur le lien existant entre l'objet et la personne : "Cet objet était utilisé par nos ancêtres pour...". Dans ce cas précis, les objets sont uniquement destinés à être contemplés. Ils ont une fonction de "mémoire "et de conservation (García Canclini 1982: 144-116).

Si l'activité touristique est aujourd'hui bien rôdée et que l'ensemble de la population s'y investie en affirmant notamment son identité shuar auprès des touristes, il est néanmoins intéressant d'observer que ce phénomène de valorisation ethnique était inexistant avant le développement de l'activité touristique. II ne s'agit pourtant pas d'un simple simulacre où la population se bornerait à "jouer à l'indien" (Ramos 2004). Cette mise en scène commercialisée s'inscrit en effet dans une dynamique complexe d'ethnification dont les enjeux dépassent largement les frontières touristiques. Dans le cas de ChicoMéndez, la population s'est en effet construite avec et à travers le tourisme en se réappropriant notamment des formes de représentations culturelles en se basant à la fois sur des références propres, mais également sur l'interprétation des désirs des touristes. Afin de comprendre ce processus d'affirmation et d'appropriation identitaire, il convient de revenir sur l'historique du projet touristique.

\section{Tourisme communautaire, (ré)appropriation culturelle et affirmation identitaire}

\subsection{L'historique du projet touristique : d'une initiative individuelle à un projet collectif}

Le projet touristique communautaire Ikiam est né en 2006. Loin d'être une initiative collective, l'idée fut impulsée par Pedro Tzerembo, membre de la communauté de Chico-Méndez, mais néanmoins absent de celle-ci depuis plusieurs années pour des raisons professionnelles et universitaires. Pedro a en effet suivi une partie de sa scolarité (collège) à Quito avant de s'installer au début des années 1990 dans la région de Tena où il fut tour à tour chauffeur de taxi et professeur de taekwondo. En 1994, il obtint un poste de chef de sécurité au sein du projet de conservation Gran Sumaco (parc national Sumaco Napo Galeras), mis en place par le ministère de l'Environnement et financé en partie par l'agence allemande pour la coopération internationale. Son expérience lui permit d'obtenir un poste de technicien, chargé de veiller au bon déroulement des activités touristiques dans le parc et de suivre les communautés impliquées dans ces activités (Pacto Sumaco, Wawa sumaco, 10 de agosto, etc.). Pedro y a travaillé huit ans, y a fait des rencontres et a pris peu à peu conscience des enjeux liés à la protection de l'environnement et au développement du tourisme en Amazonie.

Encouragé par le directeur du projet, il reprit ses études en 2002, à l'âge de 32 ans, à l'Université des nationalités indiennes de l'Amazonie équatorienne (UNIDAE), à Puyo, capitale de la province de Pastaza. Son objectif était d'obtenir une licence en gestion du tourisme et de l'environnement pour pouvoir développer un projet de tourisme communautaire à Chico-Méndez.

Cette même année, il fit également la rencontre de sa femme, une métisse, qui l'appuya dans sa démarche en insistant sur l'importance pour un Indien de "valoriser" son identité:

"Miriam, ma femme, m'a dit : 'c'est avec le Shuar que je veux me marier'. Elle m'a interdit de me couper les cheveux. Elle m'a enlevé ma chaîne et ma montre qu'elle a remplacées par un bracelet et un collier traditionnel. Je me suis rendu ainsi à l'université. Je me souviens que j'avais tellement 
honte ! (...). Un jour, un professeur nous a dit : 'Les peuples indigènes doivent tout d'abord s'interroger sur leur propre identité, savoir qui ils sont, pour pouvoir décider de ce qu'ils veulent faire de leur avenir', ce qui m'a fait réfléchir (...). J'ai passé beaucoup de temps à enquêter, à lire en bibliothèque. Je lisais les écrits des anthropologues, des missionnaires (...), ils savaient beaucoup de choses. Moi, je connaissais à peine ma langue" (Pedro Tzerembo, 16 décembre 2009, Ikiam).

Pedro Tzerembo valida sa licence en 2007. Son travail de fin d'étude, intitulé Le tourisme comme alternative pour le développement communautaire de Chico-Méndez, lui permit notamment d'évaluer les possibilités de développement de cette activité dans sa communauté et de convaincre la population du bien fondé de ce projet. Parallèlement, il obtint un poste de technicien en tourisme à la mairie d'Arajuno, charge qu'il occupa de 2006 à 2009 et qui le mit en relation avec différents acteurs institutionnels, au niveau provincial et national.

En 2006, avant d'effectuer son travail de fin d'études, Pedro Tzerembo exposa son projet de développement touristique à sa famille et aux membres de la communauté. II mit notamment en avant la nécessité de valoriser la culture shuar en se présentant face à l'assemblée avec ses colliers et ses bracelets typiques:

“Mon père s'est vraiment énervé quand il m'a vu arriver ainsi, avec mes cheveux longs, mes colliers et mes bracelets typiques. II m'a dit: 'je t'ai envoyé faire des études pour que tu deviennes un monsieur, et regarde-toi, tu reviens en arrière, comme vivaient tes ancêtres'." (Pedro Tzerembo, entretien du 16 décembre 2009).

La transformation initiée par Pedro, vécue comme une "réinvention de soi" à travers la valorisation de "signes extérieurs" d'identification shuar, s'inscrit dans un contexte particulier de revendication identitaire valorisée sur la scène nationale et transnationale, mais elle reste finalement peu comprise des communautés locales. Cette incompréhension peut créer des tensions intergénérationnelles, familiales et/ou sociales, la condition indienne étant encore trop souvent perçue comme une situation antinomique à celle d'homme respecté et éduqué.

Pour comprendre la réaction de Jorge, le père de Pedro, il faut remonter aux origines de la communauté. Cette dernière fut créée en 1967 par le père de Jorge. Ce dernier souhaitait offrir de nouvelles terres à ses enfants, le canton de Méndez (province de Morona Santiago) dont ils étaient originaires étant confronté à l'invasion des colons et au développement intensif de l'élevage. La communauté pris le nom de son canton d'origine et fut la première communauté shuar de la zone, principalement peuplée de Quichua et de Huaorani. Dans le canton d'Arajuno, les Shuar ne représentent en effet que $3 \%$ de la population (2) répartis dans deux communautés, Chico-Méndez et Shuar Washients. Les Shuar font partie du groupe ethnolinguistique Jivaro au même titre que les Shiwiar, les Achuar, les Awajún et les Huambisa. Leur territoire traditionnel est séparé en deux par la frontière entre le Pérou et l'Équateur. En Équateur, la majorité des Shuar vit dans les provinces de Morona-Santiago (territoire traditionnel), Pastaza et Zamora Chinchipe, mais ils sont également aujourd'hui largement représentés dans les provinces de Sucumbios, Orellana, Napo, et sur la côte, dans la province d'Esmeraldas. Selon le recensement de 2010, leur population est estimée à 79.709 habitants.

Les Shuar ont été l'objet de nombreuses études anthropologiques notamment concernant leurs techniques et traditions guerrières, en particulier le rituel de la tsantsa qui consistait à réduire les têtes des ennemis vaincus. Cette pratique leur a notamment valu d'être considéré comme un peuple de farouches guerriers (Taylor 1985 et 1994). Ceci explique notamment en partie que l'intégration des Shuar de Chico-Méndez au canton à la fin des années 1960 fut délicate. Leur réputation a en effet donné lieu à de nombreux fantasmes et provoqué une certaine méfiance chez la grande majorité de la population.

"Cela a été très dur pour nous dans cette communauté. Nous sommes de Morona Santiago. Nous sommes venus ici, sur un territoire qui n'était pas le nôtre, mais celui des Huaorani et des Quichua. 'II est venu une culture étrange' disait-on. Personne ne voulait de nous. Les gens disaient que les Shuar étaient des criminels, que les Shuar coupaient les têtes, bref, que nous étions mauvais. Ils nous ont repoussés. Les temps ont changé, mais c'est toujours dur pour nous ici" (Pedro Tzerembo, entretien du 3 avril 2010).

Afin de s'intégrer à la région, les parents de Pedro et son oncle (actuellement les seuls locuteurs shuar de 
la communauté) ont fait le choix de ne pas transmettre le shuar chicham à leurs enfants. Ils souhaitaient avant tout qu'ils deviennent de "bons citoyens équatoriens", qu'ils s'intègrent à la société et à la vie cantonale, majoritairement quichua. Eux-mêmes avaient été élevés dans un internat salésien, séparés de leurs familles et dans lesquels on leur interdisait de parler le shuar (Rubenstein 2005). Les forces de domination coloniales, à la fois matérielles et symboliques, auxquelles ont été confrontés les parents de Pedro, ont participé à annihiler les formes d'expressions identitaires. Selon Jorge, ils ont "mis de côté leurs pratiques", allant jusqu'à "renier" leur origine shuar afin de "s'intégrer" à la société équatorienne ou du moins à la population quichua d'Arajuno (entretien informel du 19 mai 2011, Arajuno). L'acquisition et la transmission des pratiques culturelles et traditionnelles shuar se sont naturellement effacées au profit d'une culture quichua et métisse, dans le but de favoriser une meilleure intégration sociale de la population.

Les Shuar de Chico-Méndez se sont ainsi peu à peu intégrés à la population quichua, en suivant notamment une scolarité bilingue (espagnol-quichua), en opérant des alliances matrimoniales, et en s'affiliant aux organisations quichua, parmi lesquelles l'Association des Communautés Indiennes d'Arajuno (ACIA) et l'Association des Habitants d'Arajuno (AMA).

“Je parle plus quichua que shuar, parce que j'ai grandi avec les Quichua, depuis tout petit, dans les écoles quichua, quasiment pas avec le Shuar. J'avais presque oublié le shuar. Maintenant, je peux parler, je peux comprendre, je peux écouter, mais pas comme mes parents, très peu" (Pedro Tzerembo, 3 avril 2010, Arajuno).

Avant la mise en place du projet touristique, la culture shuar de la population de Chico-Méndez avait donc été substituée par l'adoption des modes de vie quichua et métis afin de permettre une meilleure intégration au canton. La proposition de Pedro vînt donc perturber l'ordre établi au sein de la communauté provoquant notamment certaines tensions avec les anciens et de multiples interrogations auprès de l'ensemble de la population. Pedro dut notamment mener un important travail de 'socialisation' afin de sensibiliser la communauté aux enjeux du projet, mais également aux questions identitaires, aux questions de développement, ainsi qu'aux enjeux relatifs à la protection patrimoniale, tant sur le plan économique, social, politique que culturel. A force de persuasion, Pedro a su opérer une "inversion du stigmate" (Bourdieu 1980: 69), créant une nouvelle conscience ethnique au sein de sa communauté. Les différentes réunions organisées par Pedro afin de socialiser la population aux enjeux touristiques ont notamment participé à convaincre les habitants que le patrimoine culturel est une ressource touristique et qu'il est donc possible de tirer profit de sa mise en valeur. C'est donc avant tout une conception de la culture comme capitale qui a induit celle de la culture comme patrimoine, cette observation rejoignant notamment l'analyse de Picard (2001: 118) pour qui la conception d'une culture en tant que patrimoine à préserver est possible à partir du moment où la population prend conscience de sa culture et de la possibilité de la convertir en capital à exploiter. Plusieurs études ont également montré que la commercialisation et la mise en scène touristique ne signifient pas une perte de signification et une destruction de la culture, mais que l'intégration des Indiens à l'économie de marché contribue, au contraire, à la (re)construire, la (re)produire, la maintenir et/ou la reformuler (Cohen 1988, Comaroff et Comaroff 2009, Santana 2003, García Canclini 1982).

\subsection{Un processus de (ré)appropriation identitaire}

La socialisation a également favorisé une mise en débat des discours sur l'identité, entrainant, par là-même, un processus de construction identitaire. Elle a suscité un phénomène de "redécouverte" des pratiques culturelles et la mise en place de processus de patrimonialisation partagée, l'objectif étant de valoriser une culture, un patrimoine et une identité longtemps dénigrés par la colonisation, l'évangélisation et les politiques indigénistes. Peu à peu, l'investissement de la population a donc pris la forme de la recherche d'un "patrimoine commun "et d'un discours orienté vers la réappropriation culturelle et la transmission culturelle aux jeunes générations.

Pedro a également joué un rôle très important dans le processus de revitalisation culturelle, non pas tant par ses connaissances des pratiques culturelles, mais bien plus par son aptitude à "savoir" ce que recherchent les touristes. Son expérience professionnelle et universitaire ainsi que sa capacité à se convertir en "passeur culturel" (Martinez Mauri 2003, Boullosa Joly 2006, Ciarcia 2011), faisant le lien entre la communauté et le monde extérieur, lui ont notamment permis d'expliquer à la population locale ce que les touristes désirent expérimenter lors de leur séjour, pourquoi ils le souhaitent et comment se 
comporter en conséquence. Lors des réunions de socialisation, Pedro explique par exemple que les touristes sont à la recherche d'un air pur, non contaminé, qu'il est important de ne pas couper un arbre devant un touriste, de tuer un animal ou de jeter des déchets dans la nature. II insiste également sur l'importance de valoriser la culture shuar en s'adaptant aux désirs d'exotisme des touristes.

Le processus de revitalisation culturelle ne s'organise en effet pas uniquement sur la base d'un "retour à la tradition" mais sur la nécessité de trouver de nouvelles formes d'expression, de nouvelles manières d'appréhender la globalisation et de satisfaire la demande touristique. Au cours des activités culturelles, les Indiens sont censés valoriser une partie de leurs savoirs, de leurs techniques et de leurs pratiques, en mettant en scène la dose d'altérité nécessaire à la satisfaction des visiteurs. Mais ils doivent également s'adapter aux contraintes de l'espace-temps imposées par le marché touristique. La revitalisation culturelle des communautés passe donc par une réinterprétation des signifiants culturels afin d'adopter une "formule touristique" globalisée (Bunten 2008) à une identité locale spécifique. Ce processus passe notamment par une réappropriation et une transformation des pratiques potentiellement "touristifiables" consistant au préalable à inventorier les attractions possibles et les savoirs locaux exploitables, et à faire le point sur les manques de connaissances de la population afin de proposer des programmes de formations destinés à perfectionner les savoirs.

Dans le cadre du processus de revitalisation culturelle à Chico-Méndez, les savoirs qualifiés de traditionnels sont rapidement apparus comme une ressource importante. Or, ces savoirs, disqualifiés depuis plusieurs décennies par la modernisation technique, sont aujourd'hui très disparates et ont tendance à se fragmenter et à s'individualiser. Les modes de transmission ont notamment été menacés par de multiples facteurs, comme par exemple l'école, l'intervention d'acteurs extérieurs imposant des normes techniques contemporaines (agriculture, élevage, médecine, etc.). La production de ces savoirs, longtemps ignorée et considérée comme vouée à disparaître, a été altérée. La mise en place du projet de tourisme communautaire a donc favorisé la réhabilitation de ces savoirs "oubliés", en s'appuyant notamment sur les connaissances des "anciens". Leurs connaissances liées, entre autres, à l'usage et à la gestion des ressources naturelles, aux techniques de chasse, de pêche, de construction, de fabrication d'objets (notamment les lances), aux pratiques médicinales et rituelles, etc., sont en effet rapidement apparues comme une richesse patrimoniale qu'il fallait transmettre et valoriser.

A Ikiam, Jorge, pourtant réticent au projet touristique, s'est largement investi dans ce processus de réhabilitation culturelle. En tant qu'ancien, il fut fréquemment sollicité pour ses connaissances des pratiques shuar. II a notamment participé à la construction de la maison traditionnelle en transmettant à ses enfants les techniques de fabrication. Il a également créé, avec sa femme, un groupe de danse et de musique, alliant pas et rythmes traditionnels et "populaires". II intervient également fréquemment au cours de l'interaction avec les touristes. Jorge accueille les touristes le visage peint, vêtu de son itip (tenue typique), d'un tawaspa (couronne en plumes de toucan), de ses colliers, de ses bracelets et de sa lance. Il les accompagne à la cascade sacrée, leur raconte des mythes, le soir au coin du feu, leur apprend à utiliser la sarbacane, à fabriquer des paniers en fibre naturelle, etc. Considéré comme le sabio (savant) détenteur du savoir traditionnel, Jorge est également parfois présenté comme le chaman, uwishin, de la communauté. Le statut de chaman est toujours plus "vendeur" sur les prospectus touristiques et, bien qu'il ne se reconnaisse pas comme tel (3), ses connaissances dans les plantes médicinales et ses qualités de curandero (soigneur), sont reconnues par les habitants de la région et les touristes (4).

Jorge s'est donc réapproprié son identité par la mise en spectacle d'éléments culturels immatériels qu'il a su transformer pour répondre aux attentes des touristes et il transmet peu à peu ces savoirs à l'ensemble des acteurs communautaires prenant part à cette activité. Jorge insiste par exemple pour que les jeunes chantent en shuar et regrette que les instruments traditionnels soient délaissés au profit de la guitare électrique et du synthétiseur. Si les jeunes sont plus attirés par la cumbia moderne (genre musical répandu en Amérique du Sud) que par les anent (chants) de leurs ancêtres, Jorge reste attaché aux "traditions", constitutives, selon lui, de son "identité shuar". Aujourd'hui, il insiste d'ailleurs pour que son histoire, son savoir et son héritage culturel soient enregistrés et filmés afin, dit-il, "de ne pas oublier" (Alain 2012). En 2012, Jorge et sa femme, Maria, ont demandé à Arnaud Alain, alors étudiant en master d'anthropologie visuelle à la FLACSO et présent à Arajuno afin de réaliser un documentaire dans le cadre de son travail de fin d'étude, à être filmés en tenue traditionnelle, chantant et jouant de la flûte. Les images ont été tournées dans leur ferme et à la cascade Arutam, à la demande de Jorge. II souhaitait que ce documentaire serve de "souvenir "pour ses enfants, ses petits-enfants mais également pour tous ceux 
qui regarderont le documentaire. Cette mise en scène de soi est notamment révélatrice de ce besoin de revendiquer son appartenance et d'affirmer son statut d'ancien (donc de connaisseur) auprès de spectateurs potentiels (membres ou non de sa famille). Elle se traduit également par l'affirmation d'un sentiment de fierté et d'une volonté de transmettre ses connaissances, tout en contrôlant les informations données.

Le processus de touristification a clairement transformé le rapport que Jorge entretenait à sa culture. Le rôle qui lui a été attribué l'a encouragé à valoriser son identité culturelle alors même qu'il avait fait le "choix" d'occulter son appartenance afin de s'intégrer à la population quichua et métisse du canton d'Arajuno. Les performances touristiques semblent en effet également servir d'outil de valorisation, permettant aux anciens de se présenter comme les principaux agents de la transmission de la "tradition" et, comme tel, d'acquérir un certain statut au sein de la communauté.

Les femmes se sont également investies dans le processus de revitalisation et de mise en scène des pratiques culturelles. Leur domaine d'intervention est lié à diverses compétences mais se concentre principalement, dans le cadre touristique, à celle de l'artisanat et plus particulièrement à la fabrication de poteries. Un autre domaine dans lequel les femmes interviennent est celui de la fabrication de bijoux (bracelets, colliers, boucles d'oreille) et d'objets artisanaux (sacs) destinés à la vente. Réalisés en fibres et graines naturelles ou en perles, ces parures nécessitent une connaissance du milieu (collecte de la fibre, des graines, des plumes, etc.) ainsi que des techniques nécessaires à leur élaboration. La fabrication d'artisanat n'est pourtant pas uniquement une activité féminine. De nombreuses pièces et objets sont réalisés par les hommes. La fabrication de couronnes de plume, de lances, d'instruments de musique (tambours, flutes, arc musical, etc.) et de paniers en fibre naturelle, fait notamment partie des travaux qui leurs sont attribués. Les savoirs sont généralement transmis par les anciens mais les pères de famille réapprennent également les techniques de fabrication qu'ils enseignent eux-mêmes à leurs fils. Or, une partie de ses savoirs s'était perdue à Chico-Méndez. Afin de palier à ce manque de connaissance mais aussi pour s'adapter au marché de l'artisanat touristique, une formation a été proposée aux habitants de la communauté dans le cadre du projet de renforcement de l'identité culturelle financée par le Fonds International de Développement Agricole (FIDA). La population, hommes et femmes confondus, a appris à réaliser des bijoux et des parures en perles, mais également à l'aide d'autres matières cosmétiques plus "traditionnelles" : fibre et graines végétales, plumes, dents, griffes, os, etc. Les parures en perles offrent notamment l'opportunité d'intégrer de nombreux symboles culturels (le toucan, la lance) et/ou motifs codifiés représentant le boa, la tortue, le jaguar, etc. (motifs que l'on retrouve sur les peintures corporelles et les poteries), lesquels ont tous une signification symbolique particulière. Ces perles, au départ importées par les occidentaux (perles de verre), sont devenues des objets essentiels à la fabrication des parures indiennes. Leurs couleurs et les motifs codifiés qu'elles permettent de créer en ont fait des objets de valeur constitutifs de leur identité et de leur "patrimoine". Bien que ces parures corporelles réalisées en perles soient beaucoup moins prisées par les touristes, elles sont néanmoins considérées comme des identifiants culturels importants par les Indiens. Pour répondre à la demande touristique, les habitants n'hésitent également pas à créer de nouveaux motifs clairement destinés à l'industrie du souvenir. Les bracelets en perle sont ainsi parfois ornés du drapeau de l'Equateur ou de cœurs. Sur d'autres, on peut lire "Ecuador" (Équateur), "Selva” (forêt), "Chico-Méndez" ou "Ikiam".

Pour des raisons économiques, certains hommes se sont également mis, aux côtés de leurs femmes, à la fabrication de bijoux, de parures et de céramiques. Les hommes ont suivi une formation et élaborent divers bracelets, colliers et boucles d'oreilles en perle. Ce processus s'inscrit à la fois dans une dynamique économique (vente des produits) mais également identitaire, dans la mesure où les hommes portent aujourd'hui les parures (les bracelets principalement) qu'ils ont élaborées et s'identifient, en par ce biais, à la nation shuar. Beaucoup d'hommes se sont également fait pousser les cheveux "pour faire plus shuar".

Les plus jeunes jouent aussi un rôle important dans le processus de revitalisation culturelle. Présents aux côtés de leurs parents, ils observent et apprennent diverses pratiques, notamment à travers un processus mimétique de la transmission. Dans le cadre des activités culturelles, il est fréquent de proposer un atelier de fabrication de paniers en fibre naturelle, d'organiser un concours de sarbacane ou de présenter les pièges utilisés pour la chasse et pour la pêche. C'est notamment au cours de ces "démonstrations touristiques" que les jeunes guides indiens ou les enfants présents se forment aux techniques traditionnelles. Ils aiment notamment se confronter aux touristes lors des concours de sarbacane. La 
revitalisation passe également par un processus de (ré)identification. Ainsi, les prénoms shuar, oubliés depuis trois générations, sont de nouveau utilisés. Aujourd'hui, les plus jeunes s'appellent Tuna (cascade), Tsunki (divinité de l'eau), Yaanuwa (femme étoile), Nayapi (oiseau messager), Etsa (soleil), etc. Ce processus a néanmoins une certaine limite. La majorité des jeunes refusent par exemple de se faire pousser les cheveux, arguant que les cheveux longs, c'est fait pour les filles.

\subsection{Des enjeux identitaires qui dépassent les frontières touristiques}

En développant un projet touristique, les Shuar de Chico-Méndez ont fait le choix d'affirmer leur identité. Ce processus de valorisation culturelle s'est notamment accompagné de la création de l'Association Ikiam du Peuple Shuar de Chico-Méndez en 2007, association destinée à contribuer au développement social, économique et culturel de la communauté, à promouvoir des programmes de protection et de conservation de l'environnement et à renforcer l'identité culturelle de la communauté à travers la valorisation de la langue, des coutumes, des connaissances ancestrales, spirituelles et autres.

Ce processus d'affirmation identitaire opéré à travers la mise en tourisme et officialisé par la création de l'Association Ikiam, ne fut cependant pas très bien accepté dans ce canton majoritairement quichua:

"Ça a été mal perçu par les dirigeants des autres organisations quichua. Avant, les habitants de Chico-Méndez étaient dans différentes organisations. Quand je suis revenu il y a trois ans, j'ai formé une association, j'ai socialisé pour que nous puissions nous identifier en tant que culture, comme un peuple. Je les ai alors retirés de toutes les associations et je les ai amenés ici. Nous sommes Shuar et nous devons nous identifier comme Shuar. Alors les autres se sont un peu énervés. Ils ont dit : 'Pedro est venu et les gens ne veulent plus rien savoir de nous. Tous seuls, ils sont en train de devenir forts'." (Pedro Tzerembo, 3 avril 2010, Arajuno).

Cette "prise d'indépendance" fut difficilement tolérée, conduisant notamment à une multiplication des conflits avec les Quichua. En 2009, les habitants de Chico-Méndez furent même menacés d'expulsion:

"Il y a un an, ils voulaient nous expulser d'ici. Les organisations et même le maire (d'origine quichua) se sont regroupés. Ils se sont organisés et ont voulu nous expulser en nous disant que le territoire était le leur. Mais quand mes parents ont immigré ils étaient si capables et si intelligents qu'ils sont allés à l'IERAC (Institut Equatorien de la Réforme Agraire et de la Colonisation) pour tout légaliser. Nous avons un document du gouvernement disant que nous sommes propriétaires de cette terre de 1700 ha représentant la communauté de Chico-Méndez. Nous avons dit: 'Venez, venez nous expulser. C'est ici que nous vivons et nous protégeons ce qui nous appartient. Si nous devons prendre les armes, si nous devons nous opposer, nous nous opposerons, parce que cette terre n'est pas la nôtre mais celle de nos enfants'. Nous avons lutté pour ça. Nous sommes partis jusqu'à la mairie et nous avons séquestré le maire pour qu'ils nous respectent. Tous vêtus comme des Shuar, avec nos peintures de guerre, armés. Nous avons pris du tabac, nous avons bu du huanto et nous sommes sortis nous battre. Depuis ce temps là, ils nous respectent. Bien que nous soyons peu nombreux, ils nous respectent" (Pedro Tzerembo, 3 avril 2010, Arajuno).

Auparavant affiliés aux organisations quichua, les Shuar de Chico-Méndez ne remettaient pas en cause le pouvoir, tant symbolique, numérique que politique, exercé par les Quichua dans le canton d'Arajuno. Mais en réaffirmant leur frontière ethnique, ils ont également réaffirmé leur frontière territoriale, provoquant notamment la colère des dirigeants quichua, la plupart en poste à la mairie d'Arajuno. Situation qui a notamment provoqué le renvoi de Pedro, technicien du tourisme à la mairie depuis 2006.

Le tourisme communautaire peut se révéler être un "espace de conflits" (Prieto 2011, Hall 2007). Dans le cas de Chico-Méndez, ce projet de développement a contribué à attiser des tensions ethniques, territoriales, politiques et économiques. L'affirmation identitaire des Shuar a été ressentie comme une "prise d'indépendance" remettant en cause la légitimité politique des Quichua dans le canton. Néanmoins, si les tensions interethniques existent, elles se cristallisent davantage au niveau politique (enjeux de pouvoir, de territoire et de légitimité politique). Dans le cadre du développement touristique et de la valorisation patrimoniale, la diversité culturelle est au contraire encouragée. Elle permet non seulement aux communautés d'affirmer leur appartenance ethnique mais également au canton de se construire une identité "interculturelle" valorisée par la Constitution de 2008 prônant "l'unité dans la diversité" (Acosta et Martinez 2009). 


\section{Une culture touristique?}

A Chico-Méndez, on assiste à un processus de revitalisation culturelle clairement associé à celui de la touristification. Sans le développement du projet touristique communautaire lkiam, il est peu probable que la population ait opéré un processus de réappropriation culturelle générant une telle dynamique d'affirmation et d'appropriation identitaire. En faisant de la culture shuar une des principales attractions, la population s'est en effet réappropriée des pratiques tout en les adaptant aux désirs des voyageurs ainsi qu'aux impératifs du marché touristique. Le tourisme n'incarne donc pas qu'une logique de monstration (exhibition) mais également une logique de transmission (fabriquer, transmettre, divulguer) et d'identification, impliquant d'importants remaniements culturels. Or, il est intéressant de noter que c'est principalement à travers un jeu complexe d'interactions avec les touristes et la répétition de pratiques touristifiées que la population en est venue à s'identifier, cette culture, folklorisée, ayant abouti, à une certaine forme de cristallisation dans les mentalités.

Picard (1992: 183) utilise la notion de "culture touristique" pour qualifier une culture qui a su s'adapter aux touristes et à leurs exigences. D'autres auteurs (Wood 1998, Ooi 2002, Saidi 2010) se sont également appuyés sur cette notion afin d'analyser les dynamiques culturelles à l'œuvre au sein des sociétés touristifiées. Selon Saidi (2010: 6), "Cette culture touristique comprend les expériences, les réflexes, les manières de faire, de se dé-faire et de se re-faire (Hollinshead 2004) que les sociétés d'accueil développent à force d'interagir avec les touristes et de s'exposer au regard de l'autre". Or, cette culture touristique apparaît aujourd'hui de plus en plus déterminante dans la construction des imaginaires et la production d'images entretenues et diffusées par les sociétés hôtes. En choisissant de valoriser leur patrimoine culturel, les habitants de Chico-Méndez ont du revisiter leur culture tout en sélectionnant les principaux marqueurs visibles leur permettant de s'identifier vis à vis de "l'Autre". Cette culture touristique s'est donc accompagnée d'un phénomène de patrimonialisation permettant à la population de s'identifier au sein de la communauté mais également de s'affirmer à l'extérieur, notamment vis à vis des associations quichua du canton.

A Chico-Méndez, le tourisme communautaire participe de la construction d'une identité "positive" dont la popularité, acquise auprès des touristes et des acteurs investis dans la protection des droits des minorités (ONG, institutions internationales, etc.), est notamment vécue comme une revanche sur les discriminations subies dans le passé. La mise en scène de soi n'est donc pas uniquement un artifice socio-économique dans la mesure où elle interagit également sur les définitions que se donne le groupe lui-même. Le tourisme joue notamment un rôle de réappropriation et de revendication se manifestant par le développement d'un sentiment de fierté d'appartenance ethnique:

"Nous ne trompons pas le touriste en lui disant que nous vivons ainsi, tel que je suis sur cette photo. C'est seulement un symbole. Une photo pour montrer que c'était notre culture et que nous continuons à la pratiquer pour nous identifier et dire aux touristes: 'Regardez, ainsi vivaient mes parents. Ceci est la vraie culture de nos parents et nous continuons à la pratiquer pour qu'elle ne disparaisse pas'. Et nous en sommes fiers, non seulement à présent, mais pour tout le reste de notre vie" (Pedro Tzerembo, entretien du 20 mai 2011).

Le tourisme a également joué un rôle crucial dans l'avènement d'une conscience réflexive de la culture, les métadiscours sur la culture et l'identité shuar étant aujourd'hui très présents. Le cas de Chico-Méndez ne fait cependant pas exception. D'autres études de cas on montré des processus similaires où la culture, à travers le processus de touristification, passe d'une expérience vécue (relevant de la doxa) à un statut d'“objet", de patrimoine, et d'élément d'information:

“En tant qu'objet', la culture peut être vendue, mais elle peut aussi être pensée, présentée et exposée comme 'patrimoine', comme une continuation délibérée du passé. Comme 'patrimoine', la culture devient paradoxalement détachée du vécu, un signe d'identité, tout en revêtant une charge émotionnelle inédite. Une fois détachée de soi et considérée à distance, elle devient une chose dont on peut parler et que l'on peut questionner. Bref, la culture devient un élément d'information que l'on peut fournir à autrui" (Erb 2001: 95).

Cette analyse rejoint celle d'Allart et de Vienne (2005: 134), pour qui, la culture qui se "donne à voir" a 
tendance à se limiter au sens d'un patrimoine, d'un corpus valorisé de pratiques et de savoirs. Ils mettent notamment en avant le fait que la culture s'est cristallisée pour devenir un patrimoine hérité des ancêtres, qu'il faut préserver. II ne s'agit plus d'une expérience vécue mais d'une "information" à partager, à donner à voir et/ou à vendre. C'est notamment ce constat qui a incité Carneiro da Cunha (2010) à mettre en tension culture et "culture": d'un côté "la toile invisible à laquelle nous sommes suspendus", de l'autre un "métadiscours réflexif sur la culture". Sur le terrain, la frontière entre la culture comme expérience vécue et la culture comme "objet "n'est cependant pas évidente à déterminer. Cela dépend notamment de plusieurs facteurs: d'une part, de l'usage qui est fait de la "culture", d'un point de vue collectif et du rapport que chaque individu entretient à la culture; d'autre part, du degré de touristification de chaque communauté.

A travers l'exemple de Chico-Méndez, nous avons pu voir que la "culture" joue un rôle central dans les projets de tourisme communautaire et représente également une valeur consciente qu'il faut défendre et, si nécessaire, réinventer. La notion de "culture touristique" a notamment permis de mieux comprendre la complexité des rapports et des dynamiques qui se créent au sein de l'activité touristique, tout en mettant l'accent sur le rôle actif des sociétés hôtes dans les processus de construction et de redéfinition identitaire. A Chico-Méndez, le tourisme est clairement devenu un facteur de création et de diffusion d'une identité culturelle contemporaine. II s'est transformé en un espace où se (re)définissent et se négocient les identités. Les processus de revitalisation, de mise en scène et de consommation culturelles ont en effet amené la population locale à prendre conscience de sa culture (et plus particulièrement de sa valeur économique et politique) et à transformer le regard sur Soi en incarnant, avec fierté, une identité culturelle ethnique reconstruite leur permettant de s'adapter aux transformations imposées par le monde "glocale".

\section{Notas}

1. Un saladero est une formation naturelle créée par l'érosion d'une roche et dont la terre, riche en sels minéraux, est ingérée par les oiseaux et les animaux afin de faciliter la digestion des aliments (fruits, graines, etc.). Dans le cas d'Ikiam, il s'agit d'un saladero de perroquets, lesquels viennent nombreux se nourrir aux heures matinales.

2. Le canton d'Arajuno se compose à $92 \%$ d'indiens dont la grande majorité (75\%) est Quichua (PDOT 2010).

3. Jorge ne s'autodéfinit pas comme uwishin et n'apprécie que moyennement le rôle qui lui a été attribué. Ce statut, s'il est plus attractif dans le cadre touristique, est également plus dangereux dans la vie quotidienne, de nombreux chamans étant accusés de "faire le mal" (uwishin wawékratin). Son père, chaman, a été assassiné quelques années après s'être installé à Chico-Méndez.

4. Jorge effectue des "limpiezas" (rites de purification) auprès des touristes et propose une visite du jardin médicinal.

\section{Bibliographie}

Acosta, Alberto (et Esperanza Martínez)

2009 Plurinacionalidad. Democracia en la diversidad. Quito, Abya-Yala.

Alain, Alain

2012 Miradas cruzadas en Arajuno: de la imaginación a la política. Visualidades y usos sociales del video en el marco de una etnografía audiovisual compartida. Mémoire de master en anthropologie visuelle. Quito, Flacso.

Boullosa-Joly, Maïté

2006 Re-devenir indien en Argentine: Amaicha et Quilmes à l'aube du XXIe siècle. Thèse de doctorat. 
Paris, EHESS.

Boullosa-Joly, Maïté (et autres)

2010 Tourisme patrimonial et sociétés locales, Cahiers des Amériques latines. Paris, IHEAL.

Bunten, Alexis

2008 "Sharing Culture or Selling Out? Developing the commodified persona in the heritage industry", American Ethnologist, $\mathrm{n}^{\circ}$ 35, 3: 380-395.

Ciarcia, Gaetano

2011 "Introduction", dans Gaetano Ciarcia (coord.), Ethnologues et passeurs de mémoires. Paris, Karthala: 7-29.

Cohen, Erik

1988 "Authenticity and commoditization in tourism", Annals of tourism research, $\mathrm{n}^{\circ} 15: 371-386$.

Comaroff, John (et Jean Comaroff)

2009 Ethnicity, Inc. Chicago, The University of Chicago Press.

García Canclini, Néstor

1982 Las culturas populares en el capitalismo. La Havane, Casa de las Americas.

Hall, Michael

2007 "Politics, power and indigenous tourism", dans Richard Butler y Tom Hinch, Tourism and indigenous peoples. Oxford, Boston, Paris, Butterworth-Heinemann.

Hollinshead, Keith

2004 "Tourism and New Sense : Worldmaking and Enunciative Value of Tourism", dans Michael Hall et Hazel Tucker (coord.), Tourism and Postcolonialism: Contested Discourses, Identities and Representations. Londres et New York, Routledge: 24-42.

Martinez Mauri, Mónica

2003 Médiation et développement, l'émergence des ONG et des passeurs culturels à Kuna Yala (Panama). Genève, Collection Itinéraires, $n^{\circ} 16$, Publications de l'IUED.

Ooi, Can-Seng

2002 Cultural Tourism and Tourism Cultures : The Business of Mediating Experiences in Copenhagen and Singapore. Copenhagen, Business School Press.

Picard, Michel

1992 Bali : tourisme culturel et culture touristique. Paris, L'Harmattan.

2001 "Bali : vingt ans de recherches", Anthropologie et Sociétés, n² 25: 109-127.

Prieto, Mercedes (ed.)

2011 Espacios en disputa: el turismo en Ecuador. Quito, FLACSO.

Rubenstein, Steve

2005 “La conversión de los Shuar", Iconos, n 22: 27-48.

Santana, Augustín

2003 "Turismo cultural, culturas turísticas", Horizontes Antropológicos, n 9: 31-57.

Saidi, Habib

2010 "De la culture touristique au tourisme patrimonial/From Tourism Culture to Heritage Tourism", Ethnologies, vol. 32, $\mathrm{n}^{\circ}$ 2: 5-22.

Taylor, Anne-Christine

1985 "L'art de la réduction : la guerre et les mécanismes de la différenciation tribale dans la culture jivaro", Journal de la société des américanistes, n 71: 159-173.

1994 "Una categoría irreductible en el conjunto de las naciones indígenas: los Jivaro en las 
representaciones occidentales", dans Bianca Muratorio (coord.), Imágenes E Imagineros. Quito, FLACSO: 75-107.

Wood, Robert E.

1998 "Touristic ethnicity : a brief itinerary", Ethnic and racial Studies, vol. 21, n 2: 218-241.

Gazeta de Antropología 